\section{THE SELECTIVE BACTERIOSTATIC ACTION OF GENTIAN VIOLET} BY

LAWRENCE P. GARROD, M.D., F.R.C.P.

Professor of Bacteriology in the University of London; Pathologist to an E.M.S. Laboratory,

It was first shown by Churchman (1912) that gentian violet inhibits the growth of almost all Gram-positive bacteria in a concentration permitting the growth of most Gramnegative species. That susceptibility to this action varies remarkably even among closely related Gram-positive bacteria was shown by experiments of my own (Garrod, 1933) using several strains of each of six species of Grampositive coccus, and media containing various concentrations of gentian violet, crystal violet, Hofmann violet, methyl violet, and dahlia. There was little to choose between these five dyes, and not much strain variation in resistance among the bacteria : a true picture of their behaviour could thus be obtained by averaging the whole of these results, which gave the following as the lowest concentrations completely preventing growth :

\begin{tabular}{|c|c|c|c|}
\hline \multirow[b]{2}{*}{ · } & & \multicolumn{2}{|c|}{ Average Lowest Inhibitory Concentration } \\
\hline & & In Broth & In $5 \%$ Serum Broth \\
\hline 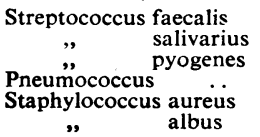 & $\begin{array}{l}\cdots \\
\cdots \\
\cdots \\
\cdots\end{array}$ & $\begin{array}{cr}1 \text { in } & 58,000 \\
, & 180,000 \\
, & 220,000 \\
& \\
, " & 1,239,000 \\
, & 1,366,000\end{array}$ & $\begin{array}{cr}1 \text { in } & 46,000 \\
\Rightarrow & 60,000 \\
\Longrightarrow & 96,000 \\
\Rightarrow & 105,000 \\
\Rightarrow & 787,000 \\
", & 1,113,000\end{array}$ \\
\hline
\end{tabular}

It thus appeared that a medium, whether enriched with serum or not, containing 1 part in 500,000 of a violet dye should inhibit the growth of any staphylacoccus and permit the growth of any streptococcus. That this was so was proved by experiment in both fluid and solid media and by their practical use for isolating streptococci from material also containing staphylococci in large numbers.

Gentian violet has sometimes been incorporated in media for such purposes as water examination, to prevent the growth of "spreaders." The aerobic spore-bearing Grampositive bacilli are in fact more susceptible to violet dyes even than staphylococci (Garrod, 1936); hence a similar medium will eliminate another genus of bacteria which in some materials is apt to be troublesome.

This method of cultivation has recently been employed with success for the isolation of haemolytic streptococci from air and dust (Andrewes et al., 1940; Bourdillon et al., 1941 ; Thomas, 1941 ; Thomas and van den Ende, 1941) and from wound exudates (Colebrook and Francis, 1941; Francis, 1941). Although its value is thus established, the full capacity of such a medium for getting rid of unwanted bacteria is perhaps not generally recognized: there are other species, particularly liable to be present in dust, which it will eliminate. Since there is no published information about the behaviour of some of these, and a general re-study would afford a coherent picture not available elsewhere, the following experiments were made.

\section{The Experiments}

Method-Agar plates were poured containing $5 \%$ of horse blood and various concentrations of gentian violet, obtained by adding a fixed volume from a series of solutions of different strength in distilled water: the concentrations throughout this series fell by one-third. Thẽ same batch of ox-heart extract peptone agar of $p \mathrm{H} 7.4$ was used throughout, and the dye was the same lot of Grübler gentian violet as I used in 1933. The properties of this dye are apt to vary, and it is advisable, in using any lot not manufactured by Grübler, first to confirm that it exerts the desired action. The plates were ruled into com- partments, and each of these was sown with a small loopful of a twenty-four-hour broth culture, the presence or absence of growth being noted after forty-eight hours' incubation.

Strains of Bacteria Used.-Gentian violet in concentrations of the order employed in these experiments has no inhibitory effect on most Gram-negative bacteria, which were therefore excluded. Those studied were Gram-positive species, whether pathogens, saprophytes, or altogether extraneous in derivation, that are apt to be found in wound exudates, on the skin, in secretions from the upper air passages, and in air or dust. The majority of the strains used were those which happened to become available from clinical material in the laboratory, and were thus of recent isolation. I am indebted to Dr. R. H. A. Swain for twelve strains of Str. viridans derived from cases of endocarditis lenta ; other strains of this organism were obtained from sputum'and saliva. All strains of Staph. pyogenes were coagulase-positive. Bacilli included seven strains of $B$.anthracis, several of $B$. subtilis, and one each of $B$. brevis, B. megatherium, $B$. mesentericus, and $B$. mycoides, for which and for several other cultures used I am indebted to the National Collection of Type Cultures. "Micrococci" included eight ștrains of $\boldsymbol{M}$. tetragenus and three of Sarcina lutea. Corynebacteria included six strains of $C$. diphtheriae and sundry diphtheroids from the nose or throat and from wounds. It was thought impracticable to test fungi other than a few strains of Monilia and Torula owing to their great multiplicity of species, but quite low concentrations of gentian violet do in fact inhibit the growth of moulds.

\section{Maximum Concentrations of Gentian Violet in $5 \% \cdot$ Blood} Agar permitting Growth

\begin{tabular}{|c|c|c|c|c|c|c|c|c|c|c|c|c|c|c|c|}
\hline & \multirow{2}{*}{ 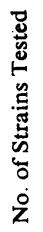 } & \multicolumn{14}{|c|}{ Concentration of Dye in Medium } \\
\hline & & 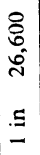 & $\begin{array}{l}8 \\
8 \\
8 \\
8 \\
\text { : }\end{array}$ & $\begin{array}{l}8 \\
8 \\
8 \\
=\end{array}$ & $\begin{array}{l}8 \\
8 \\
8 \\
8 \\
=\end{array}$ & $\left|\begin{array}{c}8 \\
8 \\
n \\
2 \\
:\end{array}\right|$ & 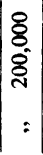 & $\left|\begin{array}{l}8 \\
8 \\
\delta \\
8 \\
0\end{array}\right|$ & $\mid \begin{array}{c}8 \\
8 \\
8 \\
8 \\
8 \\
=\end{array}$ & 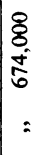 & $\left|\begin{array}{c}8 \\
0 \\
i \\
0 \\
0 \\
- \\
=\end{array}\right|$ & $\mid \begin{array}{c}8 \\
\delta \\
\infty \\
n \\
= \\
=\end{array}$ & $\begin{array}{l}8 \\
\delta \\
\tilde{y} \\
\text { în } \\
\text { í } \\
:\end{array}$ & $\begin{array}{c}8 \\
8 \\
n \\
\overline{0} \\
m \\
=\end{array}$ & 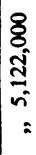 \\
\hline 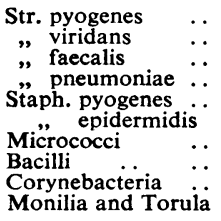 & $\begin{array}{r}16 \\
20 \\
12 \\
8 \\
18 \\
11 \\
11 \\
20 \\
15 \\
5\end{array}$ & 1 & 2 & $\begin{array}{l}3 \\
3\end{array}$ & $\begin{array}{r}9 \\
14 \\
6 \\
6\end{array}$ & $\begin{array}{l}6 \\
3 \\
2\end{array}$ & 1 & & & $\begin{array}{l}2 \\
1\end{array}$ & $\begin{array}{l}8 \\
1\end{array}$ & $\begin{array}{l}1 \\
1 \\
1 \\
5 \\
2 \\
3\end{array}$ & $\begin{array}{l}1 \\
7 \\
5 \\
2 \\
8 \\
1\end{array}$ & $\begin{array}{l}3 \\
3 \\
3 \\
3 \\
1\end{array}$ & 2 \\
\hline
\end{tabular}

The results, shown in the table, are expressed as the number of strains of each organism for which each concentration of the dye was the maximum permitting any growth whatever. In this and one or two succeeding lesser concentrations colonies were usually few, small, and atypical ; in practice it is therefore advisable to use a concentration less than the maximum tolerated by the organism to be isolated. In such well-tolerated concentrations (e.g., 1 in 300,000 or less for Str. pyogenes) growth is typical, and haemolysis is produced as in dye-free blood agar. The use of many strains of each organism shows that there is considerable strain variation in resistance. There is no evident order of resistance among streptococci such as I deduced from experiments with five different dyes in broth and serum broth, but in the present study only a single dye was used in a solid medium containing blood.

\section{Commentary}

The striking feature in the table is that, despite variations in strain resistance, a wide gap separates all streptococci from all staphylococci, other indifferent Gram-positive cocci, diphtheroids, and the aerobic spore-bearing bacilli. Since to this more susceptible group are to be added moulds and yeast-like fungi, it follows that most of the non-pathogenic flora of air and dust can be eliminated by the employment of a gentian violet medium. Its other chief use is the isolation of streptococci from skin and wound exudates 
containing so many staphylococci as perhaps to obscure streptococcus colonies in ordinary plates. Francis (1941) isolated haemolytic streptococci from 98 (32.7\%) out of 300 specimens of wound pus on gentian violet blood agar, whereas on plain blood agar they were recovered from only $68(22.7 \%)$ of these. He also observed that diphtheroids, which are often very numerous in superficial wounds, were completely inhibited. The medium used in recent studies for both these purposes-1 in 500,000 gentian violet blood agar-has been in use in my laboratory for ten years, and I have never seen any Gram-positive organism other than a streptococcus grow on it. The optimum concentration will vary somewhat with the amount of blood added, and may vary with different samples of the dye. It is important to secure a.good-one and verify its action : once identified it will last for years, since solutions are fairly stable and the quantity used minute ; 10 grammes of the dye would furnish a dozen plates a day for over a century.

REFERENCES

Andrewes, 'C. H., et al. (1940).' Lancet, 2, 770.

Bourdillon, R. B., Lidwell, O. M., and Thomas, J. C. (1941). J. Hyg., Camb. 41, 197.

Churchman, J. W. (1912). J. exper. Med., 16, 221

Colebrook, L., and Francis, A. E. (1941). Lancet, 1, 271.

Francis, A. E. (1941). Ibid., 2, 15

Garrod, L. P. (1933). St. Bart's Hosp. Rep., 66, 203.

- (1936). Proc. Second int. Congr. Microbiol., p. 37, London.

Thomas, J. C. (1941). Lancet, 2,123 .

_ and van den Ende, N. (1941). British Medical Journal, 1, 953.

\section{A TUBERCULIN AND X-RAY SURVEY OF A GROUP OF ADOLESCENT BOYS WITH SPECIAL REFERENCE TO MINIATURE RADIOGRAPHY}

BY

J. C. GILCHRIST, M.D., Ch.B.

S. H. GRAHAM, M.B., Ch.B., D.P.H., T.D.D.

Tuberculosis Physicians, Cardiff Area

AND

T. W. DAVIES, B.Sc., M.B., B.Ch., D.P.H.

Tuberculosis Physician, Swansea Area

(From the Staff of the King Edward VII Welsh National Memorial Association)

Case-finding in tuberculosis by means of tuberculin tests and radiography in groups of individuals has been carried out on a large scale on the Continent and in Americafor example, the work of Heimbeck in Norway and Opie and McPhedran in the U.S.A.-but not to the same extent in this country. The objects of such surveys have been to determine the incidence of tuberculous infection as shown by the tuberculin test, and to ascertain the presence of latent or active lesions in the lungs.

The high mortality from pulmonary tuberculosis in Wales is well known, and it is reasonable to assume that the incidence of tuberculous infection is also high. We have had no recent definite knowledge of this.

\section{Present Survey}

Boys who volunteered for the Air Training Corps had to undergo a medical examination by individual medical practitioners, and we were later given the opportunity of carrying out tuberculin tests as well as clinical and radiological examinations of their chests. Altogether 437 boys aged between 15 and 18 years, from the county boroughs of Cardiff and Swansea, were examined and radiographed by us. Tuberculin tests were carried out in 385 of them, and in 239 cases a detailed comparison was made of fullsized ( $15 \mathrm{in}$. by $12 \mathrm{in}$.) and miniature $(52 \mathrm{~mm}$. by $42 \mathrm{~mm}$.) films. On clinical examination suspicious physical signs were found in the chest in 6 cases; these included one of the two boys who were subsequently proved to have pulmonary tuberculosis.

\section{Tuberculin Patch Test}

The patch test was chosen owing to its simplicity and the speed with which it is applied. We failed to obtain the Vollmer patch (Lederle), which we had previously used, and had to substitute another preparation, which has given less well-marked reactions, as noted below. The instructions issued by the maker were carefully followed and the result was read on the fourth day.

TABLE I.-Results of Patch Tests

\begin{tabular}{c|c|c|c}
\hline Total No. & Positive & Negative & Doubtful \\
\hline 385 & $141(36.6 \%)$ & $206(53 \cdot 5 \%)$ & $38(9.9 \%)$ \\
\hline
\end{tabular}

We consider that $36.6 \%$ of positive reactions is low for a highly urbanized area, and doubt if it is a true representation of tuberculous infection in this age group. In 1929 D'Arcy Hart (1932), using the graduated intracutaneous test, found that by the age of -16 years $70 \%$ of his controls of the hospital class in London reacted positively. In America, Hetherington, McPhedran, Landis, and Opie (1934) found that in a group of 1,081 schoolboys aged 15 to 19 years $79.6 \%$ reacted positively.

In $38,(9.9 \%)$ cases the result is given as doubtful; here the skin showed only one or two small vesicles, with no surrounding erythema, and we felt that to record these as either positive or negative would be unjustifiable.

The patch test must be consiciered less sensitive than the graduated Mantoux test, but we think that our low percentage of positive, and high percentage of doubtful, reactions may be partly due to the test material used.

\section{Radiography}

TABLE II.-Results of X-ray Examinations (15 in. by $12 \mathrm{in.}$ Films)

\begin{tabular}{c|c|c|c|c|c}
$\begin{array}{c}\text { Total } \\
\text { No. }\end{array}$ & $\begin{array}{c}\text { Active } \\
\text { Pulmonary } \\
\text { Tuberculosis }\end{array}$ & $\begin{array}{c}\text { Require } \\
\text { Further } \\
\text { Observation }\end{array}$ & $\begin{array}{c}\text { Calcified } \\
\text { Primary } \\
\text { Complex }\end{array}$ & $\begin{array}{c}\text { Calcified } \\
\text { Nodes }\end{array}$ & $\begin{array}{c}\text { Normal } \\
\text { Limits }\end{array}$ \\
\hline 437 & $2(0 \cdot 46 \%)$ & $9(2 \cdot 06 \%)$ & $5(1 \cdot 14 \%)$ & $86(19 \cdot 68 \%)$ & $335(76 \cdot 66 \%)$ \\
\hline
\end{tabular}

Only $2(0.46 \%)$ cases were found to have active tuberculosis. This is not surprising, considering that in Great Britain it is in the subsequent age group that the disease becomes more manifest. We considered that $9(2.06 \%)$ cases required further observation because their radiographs showed evidence of former basal pleurisy, widely diffused hilar shadows, or localized indefinite shadowing. Only in $5(1.14 \%)$ cases were calcified primary complexes found. By "primary complex" we mean an initial tuberculous focus with involvement of the associated lymph glands.

In $86(19.68 \%)$ we agreed that calcification of hilar glands was present. Israel, Hetherington, and Ord (1941), in America, found that out of 643 prospective nurses aged 17 to $21,59(9.2 \%)$ showed calcification in their $x$-ray films. It is interesting to note here that of the boys whose films showed hilar calcification $36 \%$ were positive to the patch test, $57 \%$ negative, and 7\% doubtful.

\section{Miniature Radiography}

The technique used was that described by A. L. Cranch (1940), who was responsible for the miniature radiographic work. In 239 cases both full-sized and miniature films were taken. The tube distance for the large films was 5 feet, and for the miniatures $3 \mathrm{ft}$. 4 in., the respective exposure times being one-tenth and four-tenths of a second. 